\title{
The impact of low volume lymph node metastases and stage migration after pathologic ultrastaging of non-sentinel lymph nodes in early-stage cervical cancer: a study of $\mathbf{5 4}$ patients with $\mathbf{4 . 2}$ years of follow up

\author{
Marcin Sniadecki ${ }^{1}$, Dariusz Grzegorz Wydra' ${ }^{1}$, Szymon Wojtylak², Ewa Wycinka ${ }^{3}$, Marcin Liro' \\ Nikola Sniadecka ${ }^{4}$, Agnieszka Mrozinska ${ }^{5}$, Sambor Sawicki ${ }^{1}$ \\ ${ }^{1}$ Department of Gynecology, Gynecologic Oncology and Gynecologic Endocrinology, Medical University of Gdansk, Poland \\ ${ }^{2}$ Department of Pathology, Medical University of Gdansk, Poland \\ ${ }^{3}$ Department of Statistics, Faculty of Management, Gdansk University, Sopot, Poland \\ ${ }^{4}$ Department of Chemical Technology, Faculty of Chemistry, Gdansk University of Technology, Gdansk, Poland \\ ${ }^{5}$ Medical University of Gdansk, Poland
}

\begin{abstract}
Objectives: To assess the significance of pathologic ultrastaging (PU) of sentinel (SLN) and non-sentinel (nSLN) lymph nodes (LNs) and the influence on cancer staging in patients with International Federation of Gynecology and Obstetrics (FIGO) stage IA2-IB1 cervical cancer.

Material and methods: A retrospective study was conducted with 54 patients divided into two equal-sized groups. In test group ( $\mathrm{n} 1$ ), at least one SLN/patient was detected with blue dye. All excised LNs in this group were subjected to PU (4 $\mu \mathrm{m}$ slices/150 $\mu \mathrm{m}$ intervals) with hematoxylin-eosin staining and immunohistochemistry (AE1-AE3 antibodies). In none of the control group (n2) was PU performed, but in 2 patients SLN concept was performed. Patients in both groups underwent radical hysterectomy and lymphadenectomy. The effect of PU was expressed in puTNM and compared with both standard pTNM and FIGO systems. The influence of PU on patients' disease-free survival (DFS) and overall survival (OS) was assessed using Kaplan-Meier curves.

Results: In total, $516 \mathrm{LNs}$ were extracted (66 SLNs, 36\% bilaterally). Micrometastases (MIC) or isolated tumor cells (ITC) were detected in 34 of the 482 LNs (7.1\%), including 16 MICs and 9 ITC in non-SLNs. False negative rates were: 3.7\%/side-specific, and $7.4 \%$ /both sides. The use of PU resulted in stage change in 2 cases ( $\mathrm{N}$ and $\mathrm{M}$ status change), FIGO stage did not changed. No PU impact on DFS or OS was observed.

Conclusions: The risk of TNM stage migration in early cervical cancer is low, is more likely in inattentively evaluated patients, and has indeterminate prognostic and predictive value. Selection of cases with $\mathrm{cT} \leq 2 \mathrm{~cm}$ and cNO is sufficient to avoid the risk of improper staging.
\end{abstract}

Key words: cervical cancer; ultrastaging; non-sentinel node; micrometastases

Ginekologia Polska 2019; 90, 1: 20-30

\section{INTRODUCTION}

Sentinel lymph node detection (SLND) is a strategy involving closer inspection of the lymph nodes (LNs) which are most likely to be the first draining nodes of the tumor and to harbor malignancy [1]. The clinical use of sentinel lymph node (SLN) biopsy was a significant milestone in surgical oncology [2]. In gynecologic oncol- ogy, SLN biopsy has found its place in the surgical treatment of patients with vulvar cancer [3]. In cervical cancer (CC) and endometrial cancer, the role of SLN staining and detection is still being intensely investigated [4-7]. Cervical cancer spreads primarily locally and through the lymphatic system. LN status is one of the most important predictive and prognostic factors in early stage 
CC detection, where other metastases usually occur at more advanced stages. An increase in early CC diagnoses allows for adjusting the extent of uterine resection to the stage of the disease. The same is valid for the scope of lymphadenectomy (LND). When LN metastases is considered essential, SLND seems to be an alternative to complete pelvic LND for some patients. However, the benefits of SLND may be observed in all stages [8-11]. The method primarily allows, among others, the detection of micrometastases (MICs) that have been proven to have the same significance for the patient's prognosis as the detection of macrometastases (MAC) [6].

The US National Comprehensive Cancer Network (NCCN) strongly recommends the application of SLN concept in early-stage CC (as a part of LND - Recommendation 2A) [12], and the same is stated in the European Society of Gynecology and Obstetrics (ESGO) Guidelines [13]. Early-stage CC includes stage IIA 1 according to the International Federation of Gynecology and Obstetrics (FIGO) staging system [14] or is defined by sizes up to $2-4 \mathrm{~cm}$ $[11,13,15]$.

The lymph node sparing approach induces some uncertainties. It is possible that small metastases (MICs) may stay occult unless a non-SLNs (nSLNs) assessment is performed. Recently, FIGO finally added LNs status to their staging system, because the $\mathrm{N}$ feature is the most important prognostic factor in many cancers [14]. Unfortunately, imaging methods for smaller metastases (up to $5 \mathrm{~mm}$ ) still have their limitations $[16,17]$.

\section{Objectives}

The aim of this study was to assess the risk of non-sentinel low volume LN disease (LVLND) coverage of MIC and/or isolated tumor cells (ITC) in cases of both positive and negative SLN, when all LNs are examined by pathological ultrastaging (PU) in early-stage CC. Therefore, it was expected that the histopathological evaluation of all LNs ( $\mathrm{nSLNs}$ ) by PU should validate SLND as a method.

Meanwhile, PU, a non-routine method used for evaluation of LNs, may potentially allow the post-operative detection of stage migration. Clarifying the extent and role of such migration is important in the context of the adequacy of surgical recovery and adjuvant therapy planning.

Comparing the FIGO and TNM staging systems, as well as TNM including PU, together with understanding the significance and possible threats of cancer staging changes are important for enabling us to balance therapy between the desire to minimize unfavorable sequelae of surgery and maximize the oncological outcomes.

\section{MATERIAL AND METHODS}

Between the $1^{\text {st }}$ of January 2010 and the $30^{\text {th }}$ of April 2014, 122 patients undergoing surgery for CC FIGO stage IA to IIA2, were entered into the study database, 54 of them were FIGO IA2-IB1. This group of 54 patients was divided into two equal groups: $\mathrm{n} 1$ (PU performed) and $\mathrm{n} 2$ (control, no PU performed). Group $\mathrm{n} 1$ included 1 case of SLND alone, 26 cases of SLND within LND, and the re-evaluation of all extracted LNs. Group n2 included 25 cases of LND without SLN concept, and 2 cases of unsuccessful SLND. All patients underwent surgery suitable to their FIGO stage according to the current NCCN guidelines. The patients either received cisplatin-based chemoradiation, or only underwent surgery where adjuvant treatment was not advisable.

\section{Technique}

Before surgery, $1 \mathrm{~mL}$ (10 mg) of methylene blue (Sterop Pharmacobel, Belgium) was injected in each of four punctures of the vaginal portion of the cervix $(22 \mathrm{G})$ in the 3,6, 9 and 12 o'clock locations, approximately $0.5 \mathrm{~cm}$ from the tumor border, and perpendicular to the cervix surface. This was administered 10-15 minutes prior to surgical skin incision and 20-25 minutes prior to opening of the retroperitoneal space. Then the radical hysterectomy was performed (Piver class III in most cases) [18]. The LNs were considered as "sentinel" by their blue staining as specified by the surgeon intraoperatively or by the pathologist postoperatively (in cases where the staining was invisible macroscopically). Lymph nodes were removed by separating the labeled (SLNs) from the non-labeled nodes ( $\mathrm{nSLNs}$ ). If there was no labeling on a side, all LNs on that side were regarded as nSLN.

\section{Staging procedure}

Lymph node samples were embedded in paraffin blocks and subjected to standard histopathological analysis. After the final diagnosis was provided, the LNs were subjected to multiple sectioning every $150 \mu \mathrm{m}$ and evaluated by PU. In brief, the method is based on layered cutting of the paraffin-embedded tissues in $4 \mu \mathrm{m}$ micro cuts at even distances apart $(150 \mu \mathrm{m})$. The slices were placed on silanized glass slides, two samples from each level, the first stained with hematoxylin and eosin (HE), and the second subjected to immunohistochemistry (IHC) with cytokeratin (CK) monoclonal antibodies AE1/AE3 (Dako, Denmark). LNs were simultaneously examined by two researchers (MS and SW) under an optic microscope and measured manually (the maximal diameter of each lesion was noted). The schematic representation of a LN with MAC, MIC and ITC is shown in Figure 1. The occurrence of MAC or MIC, and of ITC, in each LN that had been 


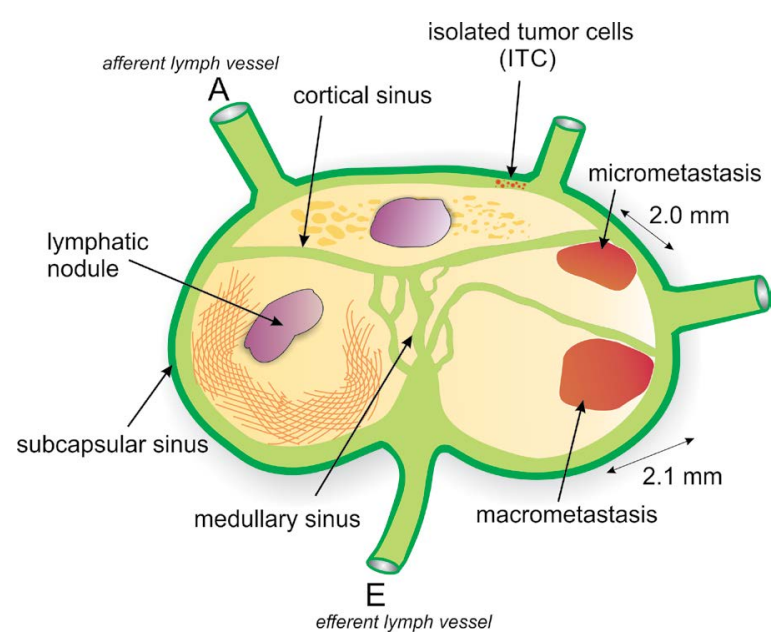

Figure 1. Schematic representation of the definitions of macro-, micrometastases and isolated tumor cells

removed was determined separately. The results have been included in their entirety in the classification of pathological (p) TNM as "puN1", "puN1 mi" and "puNOi (+)". In the latter two cases, if the LNs contained only MIC(s) and/or only ITC, the number of LNs involved are given in brackets, for example: "puN1 mi,I (+) (3LN, 1LN)". If the LNs contained MAC or MIC/ITC, this information is given at the end of Figure 1 in parentheses. With respect to SLNs, it was assumed that in cases of the successful staining of one or both sides of the pelvis the additional information on the ratio of positive LNs to the number of SLNs should be given in parentheses.

\section{Statistical analysis}

The study involved the independence chi-square test to analyze the relationship between dichotomous variables. In cases of quantitative predictors, a normality assumption was evaluated using Kolmogorov's test with the Lilliefors correction. Then the t-Student's test was used to examine the relationship between normally distributed predictors and dichotomous dependent variables, whereas the nonparametric Mann-Whitney $U$ test was used for non-normally distributed predictors. Receiver Operating Characteristic (ROC) curves were determined and the AUC (area under ROC) was calculated to obtain the power of the discriminant variables. The criterion for selection of the optimal cut-off point was the maximization of the Youden index. In all the tests, the significance level was $p=0.05$, and analysis was performed using Statistica 10 (StatSoft Inc., Poland).

\section{RESULTS}

The general characteristics of the patients are summarized in Table 1. LSVI was the only statistically sig- nificant difference between groups $\mathrm{n} 1$ and $\mathrm{n} 2$. Detailed information on cancer staging of the $\mathrm{n} 1$ group is given in Table 2. In the $\mathrm{n} 1$ group, the bilateral detection of SLN was found in 11 of 27 patients (36\%), which was a total of 38 hemi-pelvises out of 54 (70\%). A total of 516 LNs (5599 slides) were removed from the whole study group (mean 19.4 per patient), and this included 66 SLNs (12.8\%, mean 2.5 per patient). Lesions in LNs were found in 11 out of 27 patients, all at stage FIGO IB1 (2009-2017). In total, 56 LNs (10.9\%) contained lesions, and the most prevalent lesions were MAC (22 times), MIC (22 times), and ITC (12 times). Micrometastases were found in $6(9.1 \%)$ of the SLNs and in 16 (3.6\%) of the 450 nSLNs. Macrometastases were found in 7 SLNs and ITC in 3 SLNs; whereas $15 \mathrm{nSLNs}$ contained MAC and 9 nSLNs contained ITC.

Retrospectively, our intention of using SLN concept and PU allowed the detection of a larger number of LNs compared with a routine approach with surgery and examination (resulting in an average increase of $4 \mathrm{LNs}$ extracted, $p=0.046)$. On average, patients with unilateral staining were about 9.5 years older than those identified with bilateral SLND ( $p=0.0326)$. In 10 cases, MIC was found in both examinations ( $\mathrm{HE}$ and $\mathrm{IHC}$ ), and in 1 case by $\mathrm{IHC}$ only. In 3 patients, metastasis or ITC in LNs were found in the SLN(s) only, in 3 cases exclusively in $\mathrm{nSLN}(\mathrm{s})$, and in 5 patients, changes occurred in both SLN(s) and nSLN(s) (Tab. 3). A relationship was found between the occurrence of MAC in SLN and MIC in $n S L N(p=0.0072)$. The tumor metastases data on $L N$ status (SLN and $n S L N$ ), including the number of cases and corresponding ITC in LNs, are presented in Table 4. Quantitative and topographic division are shown in Figure 2.

\section{Prognostic factors and $n$ SLN status}

In 24 cases of $\mathrm{n} 1$ (88.8\%) the SLN status predicted the status of nSLN. In the $n 1$ group the sensitivity and specificity of SLN detection per site was $60 \%$ and $89.3 \%$, respectively. Lesions in nSLN were significantly more frequent if the primary lesion was $>2 \mathrm{~cm}$ than for those of $\leq 2 \mathrm{~cm}$ (73\% vs $27 \%$, respectively, $p=0.01068$ ); and in the cases of a positive LVSI the significance was $p=0.04285$. The histological type of tumor, grade and depth of infiltration did not show any statistically significant relationship with MAC, MIC and ITC detected in all LNs and in the subgroup of nSLNs as well. In patients with MACs in SLNs, the MACs and MICs in the $\mathrm{nSLNs}$ were detected significantly more frequently, without affecting the incidence of ITC ( $p=0.0142)$. The cutoff value of invasion depth for the risk of events in LNs was $\geq 8 \mathrm{~mm}$ as measured by Youden's index (Fig. 3).

\section{False negatives cases}

Results considered as false negative cases, were found in three patients of $\mathrm{n} 1$. The actual false negative 
Table1. Patients and tumor characteristics in study $(\mathrm{n} 1)$ and control $(\mathrm{n} 2)$ groups

\begin{tabular}{|c|c|c|c|}
\hline Group & n1 = $27(\%)$ & n2 = 27 (\%) & p-value \\
\hline $\begin{array}{l}\text { Age (median age } 54 \text {, range } 23-65 \text { ) } \\
20-39 \\
40-59 \\
\geq 60\end{array}$ & $\begin{array}{l}8(30) \\
12(44) \\
7(26)\end{array}$ & $\begin{array}{l}2(7.5) \\
18(66.5) \\
7(26)\end{array}$ & $P=0.354$ \\
\hline $\mathrm{BMI}^{*}$ (median, range) & $25(19-37)$ & $23(17.5-39)$ & $P=0.608$ \\
\hline $\begin{array}{l}\text { Stage according to FIGO (2009-2017) } \\
\text { IA2 } \\
\text { IB1 }\end{array}$ & $\begin{array}{l}1(96) \\
26(4)\end{array}$ & $\begin{array}{l}2(7.5) \\
25(92.5)\end{array}$ & $P=0.55245$ \\
\hline $\begin{array}{l}\text { Type of surgery } \\
\text { PRS II (pLND) } \\
\text { PRS III (pLND) } \\
\text { PRS III (p+paLND) } \\
\text { PRS III (pLND) } \\
\text { PRS III (SLND)* } \\
\text { PRS III (pLND) }\end{array}$ & $\begin{array}{l}1(4) \\
19(70) \\
3(11) \\
2(7) \\
1(4) \\
1(4)\end{array}$ & $\begin{array}{l}2(7.5) \\
18(66.5) \\
5(18.5) \\
0 \\
2(7.5) \\
0\end{array}$ & $\mathrm{p}^{\wedge}=0.7613$ \\
\hline Histopathological tumor size in cm (median, range) & $2.5 ; 0.6-5.5$ & $2.5 ; 0.45-6.0$ & $P=0.567$ \\
\hline $\begin{array}{l}\text { Histology } \\
\text { Squamous cell carcinoma } \\
\text { Adenocarcinoma } \\
\text { Adenosquamous carcinoma }\end{array}$ & $\begin{array}{l}24(89) \\
1(7) \\
2(4)\end{array}$ & $\begin{array}{l}25(92.5) \\
2(7.5) \\
0\end{array}$ & $P=0.308$ \\
\hline Number of resected and examined lymph nodes & 516 & 382 & \\
\hline Number of patients with positive lymph nodes (MAC+/MIC +) & $7(26)$ & $5(18.5)$ & $\mathrm{p}^{*}=0.5076$ \\
\hline Number of patients with events in lymph nodes (MAC+/-MIC+/-ITC) & $11(41)$ & $5(18.5)$ & $p^{*}=0.0706$ \\
\hline LVSI & $15(56)$ & $7(26)$ & $\mathrm{p}^{\wedge}=0.037$ \\
\hline $\begin{array}{l}\text { Grade } \\
\text { G1 } \\
\text { G2 } \\
\text { G3 }\end{array}$ & $\begin{array}{l}2(7) \\
15(56) \\
10(37)\end{array}$ & $\begin{array}{l}4(15) \\
20(74) \\
3(11)\end{array}$ & $P=0.07615$ \\
\hline $\begin{array}{l}\text { Depth of invasion } \\
\leq 10 \mathrm{~mm} \\
10.1-19.9 \mathrm{~mm} \\
\geq 20 \mathrm{~mm}\end{array}$ & $\begin{array}{l}16(59) \\
10(37) \\
1(4)\end{array}$ & $\begin{array}{l}13(48) \\
13(48) \\
1(4)\end{array}$ & $P=0.555$ \\
\hline
\end{tabular}

BS - bilateral salpingectomy; BSO — bilateral salpingo-oophorectomy; BMI — body mass index (calculated by Web application at https://www.nhlbi.nih. gov/health/educational/lose_wt/BMI/bmicalc.htm; CON - cone biopsy; FIGO - International Federation of Gynecology and Obstetrics; G - grade; pLND - pelvic lymphadenectomy; paLND — paraaortic lymphadenectomy; PRS — hysterectomy according to Piver classification; SLND — sentinel lymph nodes dissection; $\mathrm{P}$ — probability of U-Mann-Whitney test (corrected for continuity); $\mathrm{p}^{\wedge}$ - probability of the Chi-square test of independence; $\mathrm{p}^{*}$ — two-tailed test for two structure indicators

rate was $2 / 27$ (7.4\%) per patient and the side-specific false negative rate was $1 / 38(2.6 \%)$. This is due to the fact that ITC are not metastases; and in the case of the side-specific false negative, the coloration was present on the opposite hemi-pelvis to the false negative result (Tab. 5).

\section{Stage migration}

Extending the histopathological examination of all LNs allowed the identification of additional metastases in 34 of 482 LNs (7.1\%) - LVLND; comprised of 22 MIC and 12 ITC. After PU was performed, the $\mathrm{N}$ feature was adjusted to the actual stage from $\mathrm{pN} 0$ to $\mathrm{p}(\mathrm{u}) \mathrm{N} 1$ in 1 case (patient PM, detection of MIC in pelvic nSLNs, 3.7\%). In one other case, the $M$ feature was changed from $c M x$ to $\mathrm{p}(\mathrm{u}) \mathrm{M} 1$ (patient MW, PALN nSLN, 3.7\%), as shown in Tables 2 and 6 . A detailed summary of changes to both the TNM and FIGO classifications after PU was performed is presented in Table 6. These changes and the differences between the groups in the classifications prior to, and after PU did not reach statistical significance, and did not influence the results.

\section{Survival analysis}

During the observation period, with a median of 4.2years, comparing the two groups ( $\mathrm{n} 1-\mathrm{PU}$ and $\mathrm{n} 2-\mathrm{no} \mathrm{PU})$, and also comparing between the PU group of patients and those without LN-positivity (including ITC), against the control group, there was no statistically significant difference observed in either the overall survival (OS) rate or the disease-free survival (DFS) rate of the patients (Fig. 4). 


\begin{tabular}{|c|c|c|c|c|c|c|c|c|}
\hline No. & Initials & $\begin{array}{l}\text { FIGO } \\
\text { staging } \\
(2009- \\
2017)\end{array}$ & $\begin{array}{l}\text { Primary pTNM } \\
\text { after surgeryq }\end{array}$ & Restaging after ultrastaging (puTNM) & $\begin{array}{l}\text { Depth of } \\
\text { invasion } \\
(\mathrm{mm})\end{array}$ & LVSI & $\begin{array}{l}\text { Type of } \\
\text { surgery }\end{array}$ & $\begin{array}{l}\text { Lymph } \\
\text { nodes }\end{array}$ \\
\hline 1. & $J B$ & IB1 & pT1b1N0Mx & pT1b1 $(3.2 \mathrm{~cm})$ uNo $(0 / 26,0 / 5 \mathrm{sn}) \mathrm{Mx}$ & 13 & Yes & PRS III & $\mathrm{P}$ \\
\hline 2. & LM & IB1 & pT1b1N0Mx & pT1b1 $(2.7 \mathrm{~cm})$ uN0 $(0 / 24,0 / 2 \mathrm{sn}) \mathrm{Mx}$ & 15 & No & PRS III & $P+P A$ \\
\hline 3. & $\mathrm{TI}$ & IB1 & pT1b1N0Mx & pT1b1 $(3.3 \mathrm{~cm})$ uN0 $(0 / 36,0 / 3 \mathrm{sn}) \mathrm{Mx}$ & 20 & No & PRS III & $P+P A$ \\
\hline 4. & $\mathrm{OE}$ & IB1 & pT2a1N0Mx & pT2a1 $(3.7 \mathrm{~cm})$ uNO $(0 / 29,0 / 2 \mathrm{sn}) \mathrm{Mx}$ & 12 & Yes & PRS III & $P$ \\
\hline 5. & KA & $\mathrm{IA} 2$ & pT1a2N0M0 & pT1a2 $(0.6 \mathrm{~cm})$ uNO $(0 / 9,0 / 2 \mathrm{sn}) \mathrm{Mx}$ & 4 & No & PRS II & $P$ \\
\hline 6. & MM & IB1 & pT1b1N0Mx & pT1b2 $(5.5 \mathrm{~cm})$ uNo $(0 / 37,0 / 4 \mathrm{sn}) \mathrm{Mx}$ & 12 & No & PRS III & $P+P A$ \\
\hline 7. & TM & IB1 & pT1b1N1Mx & pT1b1 (2.8 cm) uN1 $(6 / 16,4 / 7 \mathrm{sn}, \mathrm{mic}) \mathrm{Mx}$ & 10 & Yes & PRS III & $P$ \\
\hline 8. & LD & IB1 & pT1b1N0Mx & pT1b1 $(0.6 \mathrm{~cm})$ uNO $(0 / 5,0 / 3 \mathrm{sn}) \mathrm{Mx}$ & 6 & No & PRS III & $\mathrm{P}$ \\
\hline 9. & WJ & IB1 & pT1b1NOMx & pT1b1 $(2.5 \mathrm{~cm})$ uNo (i+) $(0 / 8,0 / 1 \mathrm{sn}, 4 \mathrm{LN}) \mathrm{Mx}$ & 16 & Yes & PRS III (LPS) & $P$ \\
\hline 10. & JM & IB1 & pT2a1N0Mx & pT1b1 $(3.0 \mathrm{~cm})$ uNO (i+) $(0 / 12,0 / 2 \mathrm{sn}, 2 \mathrm{LN}) \mathrm{Mx}$ & 9 & Yes & PRS III & $P$ \\
\hline 11. & $\mathrm{BE}$ & IB1 & pT1b1N0Mx & pT1b1 $(0.7 \mathrm{~cm})$ uNO $(0 / 9,0 / 2 \mathrm{sn}) \mathrm{Mx}$ & 7 & Yes & PRS III & $P$ \\
\hline 12. & KT & IB1 & pT1b1N0Mx & pT1b1 (3.0) uNO (i+) (0/12, 0/2sn, 1snLN) Mx & 5 & No & PRS III (LPS) & $P$ \\
\hline 13. & PM & IB1 & pT1b1N0Mx & pT1b1 $(1.0 \mathrm{~cm})$ uN1 mi, i (+) $(3 / 5,1 / 2 \mathrm{sn}, 1 \mathrm{LN}) \mathrm{Mx}$ & 10 & Yes & PRS III & $P$ \\
\hline 14. & WW & IB1 & pT1b1N0Mx & pT1b1 $(0.8 \mathrm{~cm})$ uN0 $(0 / 17,0 / 1 \mathrm{sn}) \mathrm{Mx}$ & 5 & No & PRS III & $P$ \\
\hline 15. & $\mathrm{JL}$ & IB1 & pT1b1NOMx & pT1b1 $(2.0 \mathrm{~cm})$ uNo(i+) $(0 / 20,0 / 1 \mathrm{sn}, 4 \mathrm{LN}) \mathrm{Mx}$ & 15 & Yes & PRS III & $P$ \\
\hline 16. & SD & IB1 & pT2a1N1Mx & pT2a1 $(3.0 \mathrm{~cm})$ uN1 (19/24, 2/2sn, mic) & 4 & Yes & PRS III & $\mathrm{P}$ \\
\hline 17. & PE & IB1 & pT1b1N1Mx & pT1b1 (3.5 cm) uN1 $(8 / 19,4 / 4 \mathrm{sn}, \mathrm{mic}) \mathrm{Mx}$ & 14 & Yes & PRS III (RSO, LS) & $P$ \\
\hline 18. & WJ & IB1 & pT1b1N0Mx & pT1b1 $(0.8 \mathrm{~cm})$ uNo $(0 / 15,0 / 1 \mathrm{sn}) \mathrm{Mx}$ & 8 & No & PRS III (BS) & $\mathrm{P}$ \\
\hline 19. & OS & IB1 & pT1b1N1Mx & pT1b1 $(0.8 \mathrm{~cm})$ uN1 $(1 / 12,0 / 1 \mathrm{sn}) \mathrm{Mx}$ & 8 & Yes & PRS III & $P$ \\
\hline 20. & GB & IB1 & pT1b1N0Mx & pT1b1 $(2.4 \mathrm{~cm})$ uN0 $(0 / 53,0 / 4 \mathrm{sn}) \mathrm{Mx}$ & 5.5 & No & PRS III & $\mathrm{P}$ \\
\hline 21. & DM & IB1 & pT2a1N0Mx & pT2a1 $(2.0 \mathrm{~cm})$ uNo $(0 / 24,0 / 3 \mathrm{sn}) \mathrm{Mx}$ & 6 & Yes & PRS III (BS) & $P$ \\
\hline 22. & MW & IB1 & pT1b1N0Mx & pT1b1 $(2.0 \mathrm{~cm})$ No $(0 / 10,0 / 1 \mathrm{sn}) \mathrm{Mx}$ & 12.5 & Yes & PRS III & $\mathrm{P}$ \\
\hline 23. & BM & IB1 & pT1b1N1Mx & pT1b1 $(2.7 \mathrm{~cm})$ uN1 mi $(1 / 20,1 / 2 \mathrm{sn}) \mathrm{Mx}$ & 12 & Yes & PRS III & $P$ \\
\hline 24. & LM & IB1 & pT1b1N0 (sn) Mx & pT1b1 $(0.6 \mathrm{~cm})$ uNO (sn) $(0 / 3 \mathrm{sn}) \mathrm{Mx}$ & 6 & No & PRS III (SLND) & $P$ \\
\hline 25. & SJA & IB1 & pT1b1N0Mx & pT1b1 $(2.5 \mathrm{~cm})$ uNO $(0 / 24,0 / 3 \mathrm{sn}) \mathrm{Mx}$ & 10 & No & PRS III & $\mathrm{P}$ \\
\hline 26. & KT & IB1 & pT1b1N0Mx & pT1b1 $(0.6 \mathrm{~cm})$ uNO $(0 / 20,0 / 2 \mathrm{sn}) \mathrm{Mx}$ & 6.1 & Yes & PRS III & $P$ \\
\hline 27. & MW & IB1 & pT1b2N1Mx & pT1b2 $(4.2 \mathrm{~cm})$ uN1 $(6 / 27,0 / 1 \mathrm{sn}, \mathrm{mic}) \mathrm{M} 1$ & 19 & No & PRS III & $\mathrm{P}+\mathrm{Pa}$ \\
\hline
\end{tabular}

BS - bilateral salpingectomy; BSO — bilateral salpingo-oophorectomy, i (+) — presence of ITC; LND — lymphadenectomy; No. — case number; LPS — laparoscopy; P — pelvic lymphadenectomy; PA — para-aortic lymphadenectomy; PRS II,III - Piver-Rutledge-Smith surgery type II,III; R/LS — right/left salpingectomy;

$\mathrm{R} / \mathrm{LSO}$ - right/left salpingo-oophorectomy; SLND — sentinel lymph node(s) dissection; $\uparrow$ based on routine sectioning of specimens; $\cdot$ based on ultrathin sectioning

\section{DISCUSSION}

The purpose of our study was to evaluate the reliability of the determination of metastases in nSLNs by examining the presence of any type of tumor deposits (MAC, MIC, ITC) in early-stage $\mathrm{CC}$ and by comparing the outcomes with a group of patients without sentinel concept. Using one labeling method ( $36 \%$ with double-sided staining), the false positive rate was $3.7 \%$ for hemipelvis, and $7.4 \%$ in total. In this study, a change of $\mathrm{N}$ stage (from pNO to puN1) took place in one case. In one out of four cases of para-aortic lymph nodes (PALNs) removal, an unstained LN with MIC (distant metastasis) was confirmed, resulting in the change of that patient's cancer stage (puM1). The metastatic lesion size was $2 \mathrm{~mm}$, which was initially invisible in routine processing. There were no differences in survival between groups, but the groups differed in their LVSIs and the number of LNs removed. The first issue of differing LVSIs can be explained only by contingency, and the latter of the number of $\mathrm{LN}$ s removed, by improved "navigation" in the pelvis using SLND. Besides these facts, the ultrastaging patients' material was collected after that of the non-ultrastaging ones. There was no influence of $\mathrm{PU}$ on the prognoses, which may be an effect of the small size of our study group $(n=27)$ which would impact the statistically defined differences, and in such a case, even a $15-20 \%$ difference in hazard ratio will be insignificant.

In this study only one marking method was utilized - blue dye. In our previous study, the bilateral detection 
Table 3. Cases of events in lymph nodes from the test group ( $\mathrm{n} 1$ ) with additional information on tumor size, ultrastaging, SLN identification side, SLN and nSLN condition (according to lesion domination per site and LNs) as well as detected lesions in SLN/nSLN including stained side

\begin{tabular}{|c|c|c|c|c|c|c|c|}
\hline \multirow{3}{*}{$\begin{array}{l}\text { Case number } \\
\text { (Initials, group } \\
\text { number) }\end{array}$} & \multicolumn{2}{|c|}{ SLN detection } & \multicolumn{4}{|c|}{ LN condition } & \multirow{3}{*}{ Positive, indeterminated or other } \\
\hline & \multirow{2}{*}{ Right side } & \multirow{2}{*}{ Left side } & \multicolumn{2}{|c|}{ Right side } & \multicolumn{2}{|c|}{ Left side } & \\
\hline & & & SLN & nSLN & SLN & nSLN & \\
\hline 1. (TM) (7) & + & + & MAC (1) & - & MAC (1) & - & MAC (1) and MIC (1) in indeterminated LNs \\
\hline 2. (WJ) (9) & - & + & - & - & - & ITC (4) & \\
\hline 3. (JM) (10) & + & - & ITC (1) & ITC (1) & - & - & \\
\hline 4. (KT) (12) & + & - & ITC (1) & - & - & - & \\
\hline 5. (PM) (13) & + & + & - & - & MIC (1) & $\begin{array}{l}\text { MIC (2) } \\
\text { ITC (1) }\end{array}$ & \\
\hline 6. (JL) (15) & - & + & - & - & ITC (1) & ITC (2) & ITC in left parametrial LN (1) \\
\hline 7. (SD) (16) & + & + & MIC (1) & $\begin{array}{l}\text { MAC (2) } \\
\text { MIC (6) }\end{array}$ & MAC (1) & $\begin{array}{l}\text { MAC (7) } \\
\text { MIC (2) }\end{array}$ & \\
\hline 8. (PE) (17) & + & + & MAC (1) & - & MAC (3) & $\begin{array}{l}\text { MAC (3) } \\
\text { MIC (1) }\end{array}$ & \\
\hline 9. (OS) (19) & - & + & - & MAC (1) & - & - & \\
\hline 10. (BM) (23) & + & + & MIC (1) & - & - & - & \\
\hline 11. (MW) (27) & + & - & - & MIC (2) & - & $\begin{array}{l}\text { MAC (1) } \\
\text { MIC (2) }\end{array}$ & MIC (1) in paraaortic LN \\
\hline
\end{tabular}

‡ according to TNM system (2010); LN — lymph node; MAC — macrometastasis; MIC — micrometastasis; ITC — isolated tumor cells; SLN — sentinel lymph node; nSLN - non-sentinel lymph node

Table 4. Lymph nodes' events deciding on staging in 11 patients with division into sentinel lymph nodes (SLNs) and non-sentinel lymph nodes (nSLNs) and isolated tumor cells (ITCs)

\begin{tabular}{|l|l|l|l|l|}
\hline $\begin{array}{l}\text { SLN } \\
\text { status }\end{array}$ & $\begin{array}{l}\text { nSLN } \\
\text { status }\end{array}$ & $\mathbf{n}[\%]$ & SLN-ITC & nSLN-ITC \\
\hline- & - & $4(36.36)$ & 3 & 2 \\
\hline- & + & $2(18.18)$ & 0 & 0 \\
\hline+ & - & $1(9.09)$ & 0 & 0 \\
\hline+ & + & $4(36.36)$ & 0 & 1 \\
\hline ALL & & $11(100)$ & 3 & 3 \\
\hline
\end{tabular}

Chi-square test, $\mathrm{p}=0.12168$ - no statistically significant relationship; Left side of the table: positive (+) SLN or nSLN is the diagnosis of macrmetastasis(es) or micrometastasis(es) in the lymph node, ITC - isolated tumor cells; Right side of the table: the number of ITC cases in the sentinel (SLN-ITC) and non-sentinel (nSLN-ITC) lymph nodes, respectively

rate was $66 \%$ while using a three-step combined technique [19]. Taking the false negative results per side in our current study $(3.7 \%)$ and the results per both sides of the previous study (3\%), the feasibility of SLND is almost the same. The literature also describes cases of very low detection in cases of double marking [20]. Van de Lande et al. published their systematic review, summarizing 23 studies (842 patients) with early-stage CC, indicating no difference in the cumulative sensitivity analysis of SLN detection of a combined technetium-colloid (99mTc) with the blue dye method in comparison with blue dye staining alone [21].
A high percentage of unilateral SLN detection may be caused by a significant number of tumors being between 2 and $4 \mathrm{~cm}$ (median diameter $2.5 \mathrm{~cm}$ ) or by the learning curve of performing injections. Both could affect the distribution of blue dye along lymphatic channels. However, due to SLN definition, it is doubtful whether, in the absence of bilateral SLN detection, the LNs removed from the non-marked side can be named as nSLN. Having nSLN on the non-marked side seems to be reasonable given the assumption that, despite the bilateral cervical flow of the lymph, the SLN may exist only on one side and is therefore independent of the method's lymphatic marking ability. Notwithstanding, the aim of our present study was to evaluate the prevalence of LVLND in all the LNs detected with PU performance, irrespective of the quality of administration.

Even though the subject of SLN in CC is not new, there are still only a few studies dedicated to nSLN. According to the authors' knowledge, only 10 studies on PU in early-stage CC, including evaluation of non-SLNs, have been published up to the date of our study (Tab. 7) [22-31].

Marchiole and co-authors [30] in early 2000 evaluated material like ours (574 LNs in 29 patients with CC IA1 [LVSI+] - IB1 FIGO stages), in most cases (27/29) using a single staining method. They stated that the number of false negative results was too high (13\%) to recognize SLND as safe.

Slama et al. examined 225 patients with CC (FIGO IA2-IIB) in a situation in which at least one SLN was detected with 


\section{lymph nodes with MAC}

lymph nodes with MIC

lymph nodes with ITC

sentinel lymph nodes with MAC

(-) sentinel lymph nodes with MIC

- sentinel lymph nodes with ITC
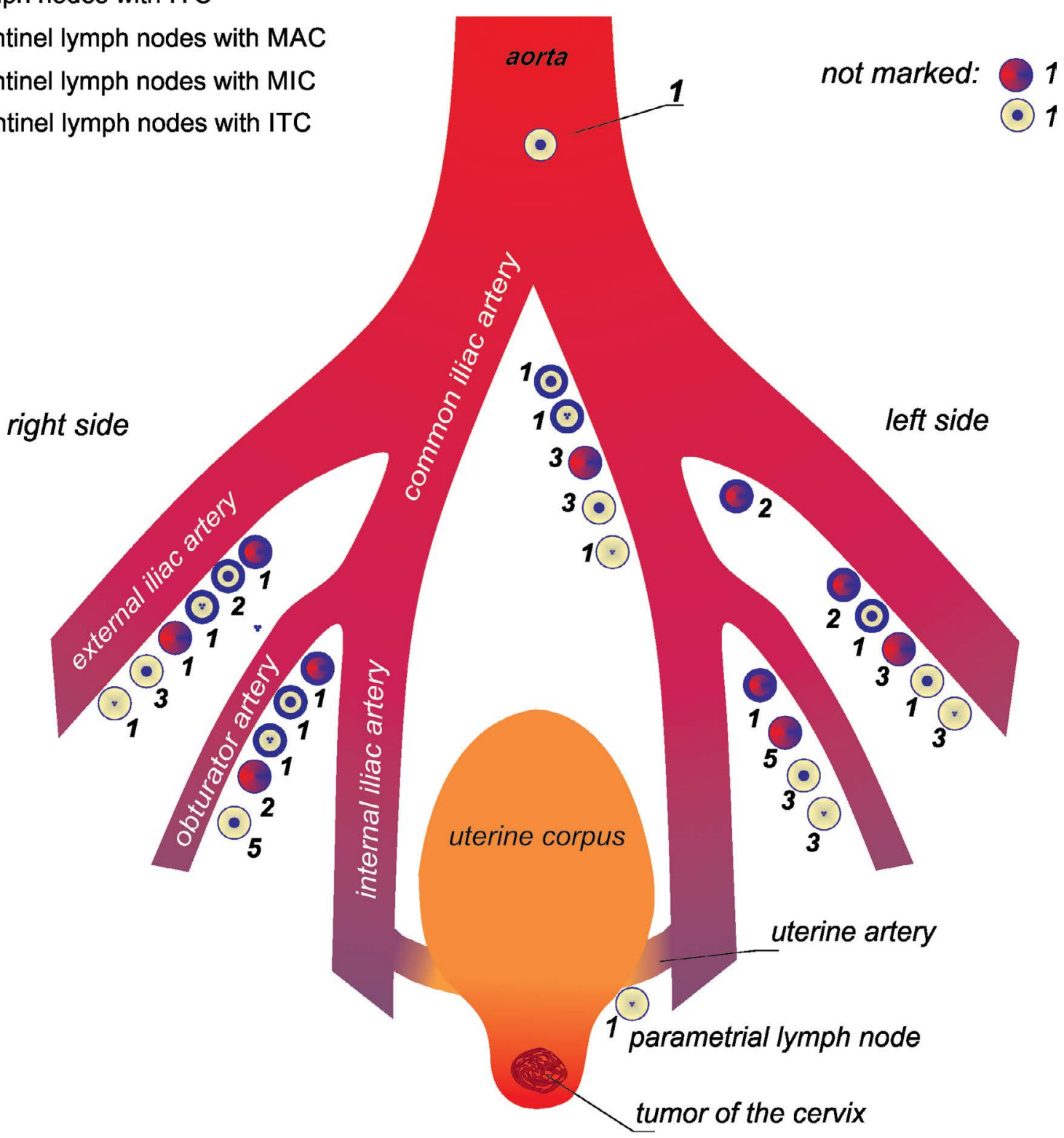

anterior aspect

Figure 2. Distribution of lymph nodes events in 27 patients with ultrastaging performed

blue dye and radiotracer and they observed a low sensitivity in establishing the SLN status [32]. The authors emphasized that a tumor size above $20 \mathrm{~cm}^{3}$ and LVSI increase the risk of a false negative result.

In the most recent research, Cibula et al. carefully selected 17 cases with CC FIGO stage IB1 ( $\geq 3 \mathrm{~cm}, 8$ patients), IB2 (7 patients), and IIB ( 2 patients), with bilateral SLN identification using an application of blue dye and radiotracer [31]. Their average of 2.5 SLNs per patient is the same as in our study. Nevertheless, Cibula et al. obtained $100 \%$ sensitivity in metastasis determination in SLN tested by PU. Due to the central position of the cervix, the possibility of obtaining false results in the SLN evaluation should be considered as associated with the side of the pelvis. We obtained similar results in our present study; however, 3 false negative results per patient 


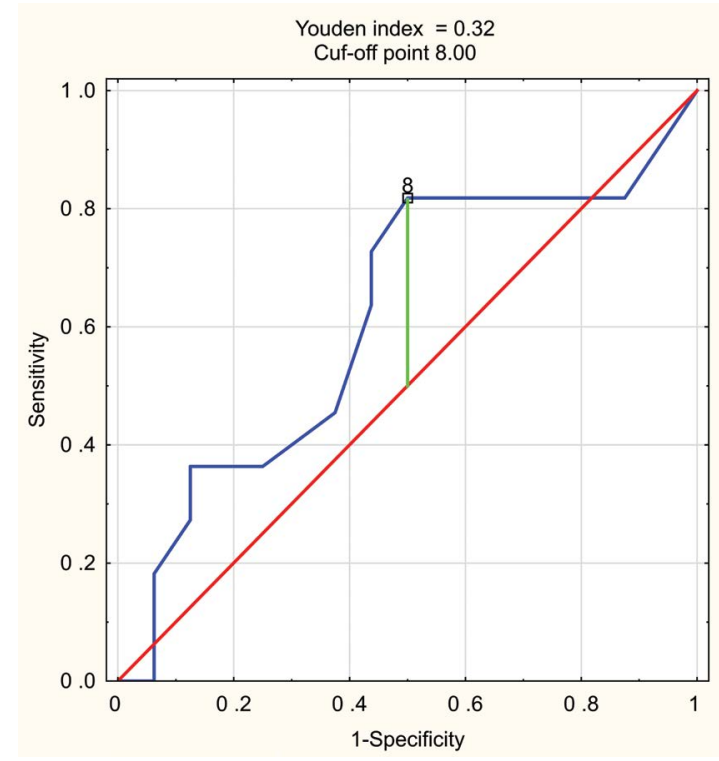

Figure 3. Graph presenting the cut-off value of the depth of tumor invasion for higher risk of invasion to lymph nodes

were found (all in cases of unilateral detection, including a case with ITC), a result that can be due to our larger study group or to our adopted definitions.

Zaal et al. examined a group of 645 CC patients (FIGO IA-IIB), and observed a prognostic benefit relating to OS and DFS, after removing more than $16 \mathrm{nSLN}$ from tumors in IB2-II FIGO stages and LVLND in SLN [33]. Fregnani et al. reported on FIGO IB-IIA cancer stages and found that only a high number of pelvic LNs ( $>20$ ) affects the prognosis [28].

Sakuragi et al. performed a study on patients with IB1-IB2 FIGO stages and determined the frequency of metastases in pelvic LNs to be $11.5 \%$, and of metastases in PALNs to be $2.1 \%$, but the prognostic impact was not evaluated [34].

Nodal and distant stage migration in the PU context has not been evaluated to date. Meva et al. performed an analysis of 54 patients with CC and presented computed tomography (CT) findings on the individual FIGO stages. The authors determined there was consistency between FIGO and pTNM in only $59 \%$ of their cases [35].

It seems clear that tumors smaller than $2 \mathrm{~cm}$ in diameter have a lower risk of nSLNs and therefore limiting surgery is safe. Hsu et al. indicated the crucial role of defining the maximal tumor diameter and proposed two scenarios for patients with FIGO stage IB1 cancer $<2 \mathrm{~cm}$ for better control of the disease, by performing parametrectomy. The system incorporated resource setting, frozen section of SLNs and age. In cases of positive SLNs on frozen section or an age $<50$ in lower resource setting, parametrectomy can be omitted [36]. However,

Table 5. False negative results per patient

\begin{tabular}{|c|c|c|c|}
\hline Case description & Type of change in the nSLN & Labeling & Commentary \\
\hline $\begin{array}{l}\text { 40-years old, BMI 19, SCC, G2, pT = } 2.5 \mathrm{~cm} \text {, invasion } \\
16 \mathrm{~mm} \text {, LVSI (+) }\end{array}$ & ITC on the labeled side & Left-sided only & $\begin{array}{l}\text { The result is actually not false } \\
\text { negative (ITC are not metastases) }\end{array}$ \\
\hline $\begin{array}{l}\text { 62-years old, BMI 29, prior conization } 3.5 \text { weeks earlier, } \\
\text { SCC, G2, pT = } 0.8 \mathrm{~cm} \text {, LVSI (-), uterine fibroids }\end{array}$ & MAC on the non-labeled side & Left-sided only & $\begin{array}{l}\text { The result is actually not false } \\
\text { negative (different sides) }\end{array}$ \\
\hline $\begin{array}{l}\text { 57-years old, BMI 22, SCC, G3, pT = } 4.2 \mathrm{~cm} \text {, invasion } \\
19 \mathrm{~mm} \text {, LVSI (-) }\end{array}$ & $\begin{array}{l}\text { MIC on the labeled and non- } \\
\text { labeled side, one paraaortic }\end{array}$ & Right-sided only & The result is false-negative \\
\hline
\end{tabular}

BMI — body mass index; G — grade; ITC — isolated tumor cells; MAC — macrometastasis; LVSI — lymph-vascular space invasion; MIC — micrometastasis; SCC - squamous cell carcinoma

Table 6. Changes in the TNM staging system after histopathological ultrastaging in the test group $(\mathrm{n} 1=27)$

\begin{tabular}{|c|c|c|}
\hline Feature & Change & Difference \\
\hline \multirow{4}{*}{ Stage } & $\begin{array}{l}\text { - clinical (FIGO) vs. pathological } \\
\text { ultrastaging, p(u)TNM }\end{array}$ & 5 cases (no. $4,10,16,21,27$ ) \\
\hline & $\begin{array}{l}\text { - in pathology review: routine (standard processing) } \\
\text { vs. ultrastaging } \\
\text { 1. T feature } \\
\text { - from pT1a2 in } p(u) T 1 b 1 \\
\text {. from pT2a1 in } p(u) T 1 b 1\end{array}$ & $\begin{array}{l}1 \text { case }(\text { no. 6) } \\
1 \text { case }(\text { no. 10) }\end{array}$ \\
\hline & 2. $\mathrm{N}$ feature - $\mathrm{pN} 0$ in $\mathrm{p}(\mathrm{u}) \mathrm{N} 1$ & 1 case (no. 13) \\
\hline & 3. $M$ feature - $p M x$ in $p(u) M 1$ & 1 case (no. 27) \\
\hline \multirow[t]{2}{*}{ Potential change in prognosis } & As a result of change in $N$ feature & No differences in OS and DFS (no. 13) \\
\hline & As a result of change in $M$ feature & No difference in OS and DFS (no. 27) \\
\hline
\end{tabular}

DFS — disease free survival; FIGO — International Federation of Gynecology and Obstetrics; OS — overall survival; TNM — Tumor, Node, Metastasis system 
A)

- complete + censored

Gehan test: $p=0.3641$

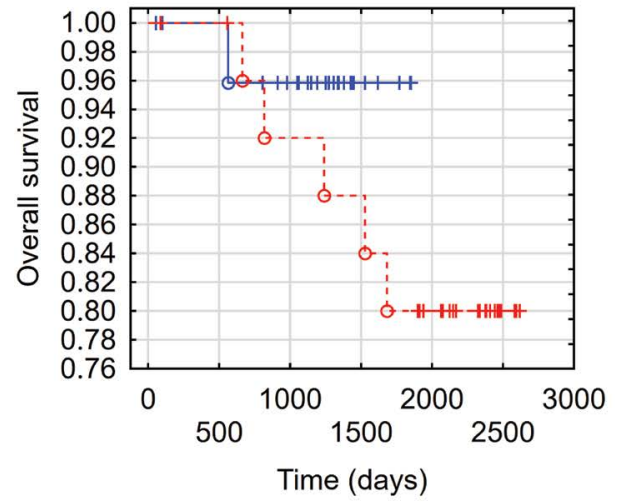

C)

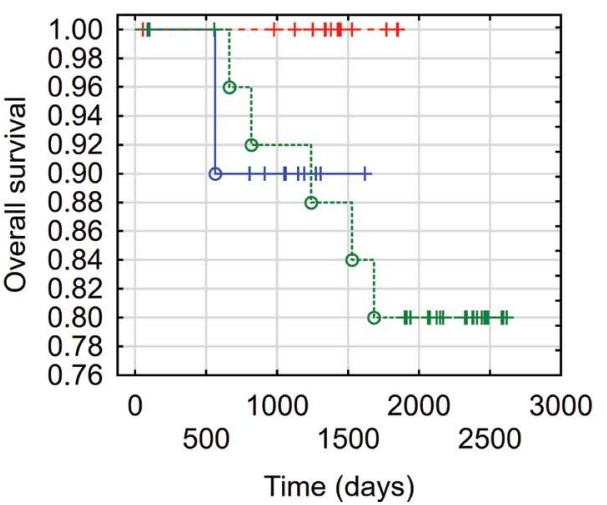

B)

$p=0.3663$

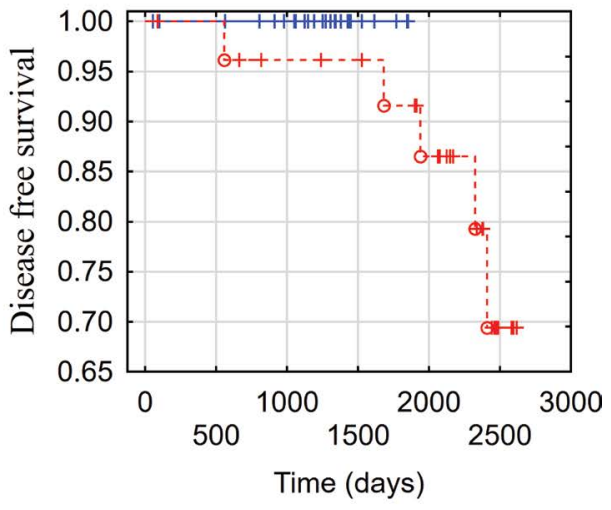

D)

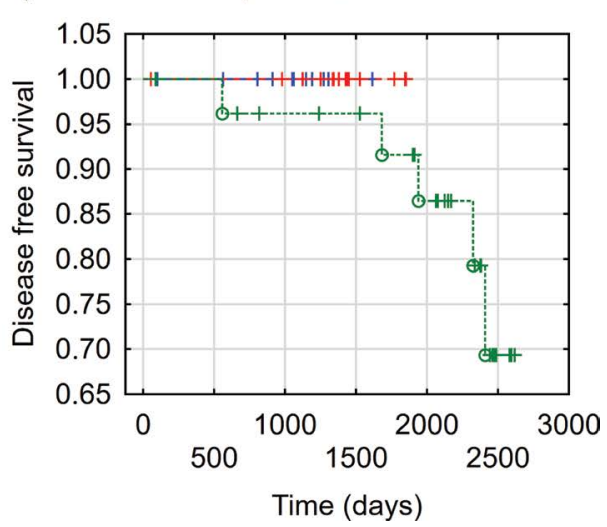

Figure 4. Overall and disease-free survival analysis of patients' study groups: A) overall survival and B) disease-free survival among ultrastaging group and control groups, C) overall survival and D) disease-free survival among LN positive and LN negative ultrastaging subgroups, and control group

their study was on "very early", rather than "early" cancer stages $[11,15]$.

The under-staged patient in our study was the one who had the second largest tumor, $\mathrm{pT}=4.2 \mathrm{~cm}$. Two $\mathrm{pT} 1 \mathrm{~b} 2$ cases ( $\mathrm{pT}=4.2 \mathrm{~cm}$ and $\mathrm{pT}=5.6 \mathrm{~cm}$ ) showed the deficiencies of the clinical classification. Additionally, there were 6 positive LNs detected, with tumor infiltration depth of $19 \mathrm{~mm}$, without LVSI positivity. Application of SLND procedures indicates that possible intra- and postoperative decisions should be categorically restricted to smaller tumors (according to literature: $<4 \mathrm{~cm}$, preferably $\leq 2 \mathrm{~cm}$ or $\leq 20 \mathrm{~cm}^{3}$ ). Although imaging modalities have not been adopted in FIGO staging requirements and TNM, it is only rarely use in CC staging for early stage patients. Our study supports the usefulness of assessing tumor diameter, or volumetric modality (with ultrasound or MRI), which is also what the ESGO guidelines noted [13].

\section{CONCLUSIONS}

Micrometastases in early-stage CC (FIGO IA2-IB1) occurs 2.5 times more often in SLNs than in nSLNs. Their detection is possible by extending the histological exami- nation by PU. The risk of finding MICs in nSLNs increases with tumor size $(>2 \mathrm{~cm})$ and with the infiltration of the lymphatic perivascular space (LVSI). Utilization of PU allows information on the actual CC clinical stage to be obtained. The SLN status determines the state of the remaining $L N s$ so long as there is a bilateral identification of SLN. In the absence of SLN detection on one side one cannot reliably conclude on the status of the nodes on the ipsilateral side since there is the risk of obtaining a false diagnostic result and of underestimating the stage. Although selection of cases with $\mathrm{cT} \leq 2 \mathrm{~cm}$ and $\mathrm{cNO}$ does not eliminate the risk of improper staging, stage migration in early CC, due to incorporation of pathologic ultrastaging, is less probable and yet, has an immeasurable prognostic and predictive impact. The only way the prognosis would be different will be where PU identifies metastases that would warrant adjuvant therapy in a setting that would otherwise not receive adjuvant therapy.

\section{Acknowledgments}

Authors thank Adam Sobieraj, MD, for his careful proofreading and critical remarks. 
Table 7. Previous studies in which patients had ultra-thin cutting of SLN and nSLN and staining in hematoxylin and eosin, immunohistochemistry, or otherwise

\begin{tabular}{|c|c|c|c|c|c|c|c|c|c|}
\hline Author & $\begin{array}{l}\text { Cancer } \\
\text { stage } \\
\text { FIGO } \\
(2009- \\
2017)\end{array}$ & $\begin{array}{l}\mathrm{N} \\
\text { patients }\end{array}$ & $\begin{array}{l}\text { Patients } \\
\mathrm{N}+ \\
\text { (MAC) }\end{array}$ & $\begin{array}{l}\text { Patients } \\
\mathrm{N}+ \\
\text { (MIC) }\end{array}$ & $\begin{array}{l}\text { Methods of } \\
\text { ultrastaging }\end{array}$ & $\begin{array}{l}\text { Cutting at the } \\
\text { distance }\end{array}$ & $\begin{array}{l}\text { Percent of } \\
\text { positive } \\
\text { nSLN with } \\
\text { negative } \\
\text { SLN }\end{array}$ & $\begin{array}{l}\text { N } \\
\text { lymph nodes }\end{array}$ & Ref. \\
\hline Barranger et al., 2003 & $|A 2-| \mid A$ & 13 & 0 & 0 & $\begin{array}{l}\text { HES \& IHC (CK } \\
\text { AE1-AE3) in } \\
\text { negative LNs } \\
\text { in routine } \\
\text { examination }\end{array}$ & $3 \mathrm{~mm}$ & 0 & 21 & [22] \\
\hline Marchiolé et al., 2004 & $|A|-|B|$ & 29 & 3 & 5 & $\begin{array}{l}\text { HES \& IHC (CK } \\
\text { AE1-AE3) in } \\
\text { negative LNs } \\
\text { in routine } \\
\text { examination }\end{array}$ & $200 \mu \mathrm{m}$ & 13 & 574 & [30] \\
\hline Popa et al., 2006 & I-IIA & 36 & 0 & 0 & HE \& IHC & $\begin{array}{l}40 \mu \mathrm{m} \text { for HE } \\
\text { (6 levels), } \\
\text { additional level } \\
\text { between 3th } \\
\text { and 4th was } \\
\text { examined with } \\
\text { IHC (AE1/3) }\end{array}$ & 0 & $\begin{array}{l}\geq 926 \\
\text { (The calculation } \\
\text { from indirect } \\
\text { data) }\end{array}$ & [29] \\
\hline Fregnani et al., $2006+$ & IB-IIA & 289 & 37 & 11 & $\begin{array}{l}\text { HE \& IHC (CK } \\
\text { AE1-AE3) }\end{array}$ & nd & nd & 5599 & [28] \\
\hline Okamoto et al., 2009 & IB1 & 10 & 1 & 1 & $\begin{array}{l}\text { HE \& IHC (CK } \\
\text { AE1-AE3) }\end{array}$ & $200 \mu \mathrm{m}$ & 0 & 309 & [27] \\
\hline Ogawa et al., 2010 & $\mid A-\| B$ & 82 & 31 & 8 & HE & nd & 0 & 157 & [25] \\
\hline Martínez et al., 2010 & $|A 2-| B \mid$ & 41 & 4 & 2 & $\begin{array}{l}\text { IHC (CK AE1- } \\
\text { AE3) }\end{array}$ & $200 \mu \mathrm{m}$ & 0 & 798 & [26] \\
\hline Lou et al., 2013‡ & „Early" & 30 & 9 & 68 & PCR (CK19) & nd & 18.2 & 268 & [24] \\
\hline Śniadecki et al., 2014 & $\mid A-\| A$ & 12 & 3 & $2(1)^{*}$ & $\begin{array}{l}\text { HE lub/i IHC } \\
\text { (CK AE1-AE3) }\end{array}$ & $150 \mu \mathrm{m}$ & 8 & 280 & [23] \\
\hline Cibula et al., 2016 & $\begin{array}{l}\mid \mathrm{B} 1 \geq 3 \mathrm{~cm}, \\
\mid \mathrm{B} 2, \mathrm{IB}\end{array}$ & 17 & 1 & 4 & $\begin{array}{l}\text { HE \& IHC (CK } \\
\text { AE1-AE3) }\end{array}$ & $150 \mu \mathrm{m}$ & 0 & 573 & [31] \\
\hline
\end{tabular}

CK - cytokeratin; HES - hematoxylin-eosin-safron; N+ (MAC) - macrometastases to the lymph nodes; $\mathrm{N}+(\mathrm{MIC})$ - micrometastases to the lymph nodes; nd - insufficient data; *one additional micrometastasis to macrometastasis in one of the lymph nodes; $\uparrow$ in this paper all the lymph nodes were examined in ultrastaging without performing the labeling of sentinel lymph nodes; $¥$ Article in Chinese, only summary is available

\section{REFERENCES}

1. Riveros M, Garcia R, Cabañas R. Lymphadenography of the dorsal lymphatics of the penis. Technique and results. Cancer. 1967; 20(11): 2026-2031, indexed in Pubmed: 6061637.

2. Tanis PJ, Nieweg OE, Valdés Olmos RA, et al. History of sentinel node and validation of the technique. Breast Cancer Res. 2001; 3(2): 109-112, indexed in Pubmed: 11250756.

3. Levenback CF, Ali S, Coleman RL, et al. Lymphatic mapping and sentinel lymph node biopsy in women with squamous cell carcinoma of the vulva: a gynecologic oncology group study. J Clin Oncol. 2012; 30(31): 3786-3791, doi: 10.1200/JCO.2011.41.2528, indexed in Pubmed: 22753905.

4. Diab Y. Sentinel Lymph Nodes Mapping in Cervical Cancer a Comprehensive Review. Int J Gynecol Cancer. 2017; 27(1): 154-158, doi: 10.1097/IGC.0000000000000853, indexed in Pubmed: 27792042.

5. Abu-Rustum NR. Sentinel lymph node mapping for endometrial cancer: a modern approach to surgical staging. J Natl Compr Canc Netw. 2014; 12(2): 288-297, indexed in Pubmed: 24586087.

6. Cibula D, Abu-Rustum NR, Dusek L, et al. Prognostic significance of low volume sentinel lymph node disease in early-stage cervical cancer. Gynecol Oncol. 2012; 124(3): 496-501, doi: 10.1016/j.ygyno.2011.11.037, indexed in Pubmed: 22120175.

7. Dargent D, Martin X, Roy M. Identification of a sentinel node with laparoscopy in cervical cancer. Proc SGO Meeting 2000, abstract. ; 44: 128.
8. Bats AS, Mathevet $P$, Buenerd A, et al. The sentinel node technique detects unexpected drainage pathways and allows nodal ultrastaging in early cervical cancer: insights from the multicenter prospective SENTICOL study. Ann Surg Oncol. 2013; 20(2): 413-422, doi: 10.1245/s10434012-2597-7, indexed in Pubmed: 22911367.

9. Cibula D, Abu-Rustum NR, Dusek L, et al. Bilateral ultrastaging of sentinel lymph node in cervical cancer: Lowering the false-negative rate and improving the detection of micrometastasis. Gynecol Oncol. 2012; 127(3): 462-466, doi: 10.1016/j.ygyno.2012.08.035, indexed in Pubmed: 22943880.

10. Slama J, Dundr P, Dusek $L$, et al. Sentinel lymph node status in patients with locally advanced cervical cancers and impact of neoadjuvant chemotherapy. Gynecol Oncol. 2012; 125(2): 303-306, doi: 10.1016/j. ygyno.2012.02.010, indexed in Pubmed: 22342976.

11. Rossi PJ, Horowitz IR, Johnstone PAS, et al. Lymphadenectomy for patients with cervical cancer: is it of value? J Surg Oncol. 2009; 100(5): 404-406, doi: 10.1002/jso.21330, indexed in Pubmed: 19760670.

12. NCCN Cervical cancer quidelines. Version II.2018; Available from. https:// www.nccn.org/professionals/physician_gls/pdf/cervical.pdf; NCCN. org. (2018.11.10)

13. https://www.esgo.org/wp-content/uploads/2015/12/ESGO Cervical-Cancer_A6.pdf (2018.11.10).

14. Bhatla N, Aoki D, Sharma DN, et al. Cancer of the cervix uteri. Int J Gynaecol Obstet. 2018; 143 Suppl 2: 22-36, doi: 10.1002/ijgo.12611, indexed in Pubmed: 30306584 
15. Altgassen C, Hertel H, Brandstädt A, et al. AGO Study Group. Multicenter validation study of the sentinel lymph node concept in cervical cancer: AGO Study Group. J Clin Oncol. 2008; 26(18): 2943-2951, doi: 10.1200/JCO.2007.13.8933, indexed in Pubmed: 18565880.

16. Grueneisen J, Schaarschmidt BM, Heubner M, et al. Integrated PET/MRI for whole-body staging of patients with primary cervical cancer: preliminary results. Eur J Nucl Med Mol Imaging. 2015; 42(12): 1814-1824, doi: 10.1007/s00259-015-3131-5, indexed in Pubmed: 26199113.

17. Driscoll DO, Halpenny D, Johnston C, et al. 18F-FDG-PET/CT is of limited value in primary staging of early stage cervical cancer. Abdom Imaging. 2015; 40(1): 127-133, doi: 10.1007/s00261-014-0194-x, indexed in Pubmed: 25015401.

18. Piver MS, Rutledge F, Smith JP. Five classes of extended hysterectomy for women with cervical cancer. Obstet Gynecol. 1974; 44(2): 265-272, indexed in Pubmed: 4417035.

19. Wydra D, Sawicki S, Wojtylak S, et al. Sentinel node identification in cervical cancer patients undergoing transperitoneal radical hysterectomy: a study of 100 cases. Int J Gynecol Cancer. 2006; 16(2): 649-654.

20. van Dam PA, Hauspy J, Vanderheyden T, et al. Intraoperative sentinel node identification with Technetium-99m-labeled nanocolloid in patients with cancer of the uterine cervix: a feasibility study. Int J Gynecol Cancer. 2003; 13(2): 182-186, indexed in Pubmed: 12657121.

21. van de Lande J, Davelaar EM, von Mensdorff-Pouilly S, et al. SCC-Ag, lymph node metastases and sentinel node procedure in early stage squamous cell cervical cancer. Gynecol Oncol. 2009; 112(1): 119-125, doi: 10.1016/j.ygyno.2008.09.042, indexed in Pubmed: 19007978.

22. Barranger E, Grahek D, Cortez A, et al. Laparoscopic sentinel lymph node procedure using a combination of patent blue and radioisotope in women with cervical carcinoma. Cancer. 2003; 97(12): 3003-3009, doi: 10.1002/cncr.11423, indexed in Pubmed: 12784335.

23. Sniadecki M, Sawicki S, Wojtylak S, et al. Clinical feasibility and diagnostic accuracy of detecting micrometastatic lymph node disease in sentinel and non-sentinel lyph nodes in cervical cancer: outcomes and implications. Ginekol Pol. 2014; 85(1): 10-13, indexed in Pubmed: 24505957.

24. Lou Hm, ZhuT, Shao F, et al. [Detection of micrometastases and its clinical significance in sentinel and non-sentinel lymph nodes from early cervical carcinoma]. Zhonghua Zhong Liu Za Zhi. 2013; 35(6): 434-438, indexed in Pubmed: 24119903.

25. Ogawa S, Kobayashi H, Amada S, et al. Sentinel node detection with $(99 \mathrm{~m}) \mathrm{Tc}$ phytate alone is satisfactory for cervical cancer patients undergoing radical hysterectomy and pelvic lymphadenectomy. Int J Clin Oncol. 2010; 15(1): 52-58, doi: 10.1007/s10147-009-0010-8, indexed in Pubmed: 20087618.

26. Martínez A, Zerdoud S, Mery E, et al. Hybrid imaging by SPECT/CT for sentinel lymph node detection in patients with cancer of the uterine cervix.
Gynecol Oncol. 2010; 119(3):431-435, doi: 10.1016/j.ygyno.2010.08.001, indexed in Pubmed: 20822803.

27. Okamoto $\mathrm{S}$, Niikura $\mathrm{H}$, Yoshinaga $\mathrm{K}$, et al. Detection of micrometastases in cervical cancer with a system that evaluates both sentinel and nonsentinel lymph nodes. Int J Gynecol Cancer. 2009; 19(4): 708-711, doi: 10.1111/IGC.0b013e3181a39112, indexed in Pubmed: 19509576.

28. Fregnani JH, Latorre MR, Novik PR, et al. Assessment of pelvic lymph node micrometastatic disease in stages IB and IIA of carcinoma of the uterine cervix. Int J Gynecol Cancer. 2006; 16(3): 1188-1194, doi: 10.1111/j.152 5-1438.2006.00519.x, indexed in Pubmed: 16803505.

29. Popa I, Plante $M$, Renaud MC, et al. Negative sentinel lymph node accurately predicts negative status of pelvic lymph nodes in uterine cervix carcinoma. Gynecol Oncol. 2006; 103(2): 649-653, doi: 10.1016/j. ygyno.2006.04.022, indexed in Pubmed: 16780935.

30. Marchiolè P, Buénerd A, Scoazec JY, et al. Sentinel lymph node biopsy is not accurate in predicting lymph node status for patients with cervical carcinoma. Cancer. 2004; 100(10): 2154-2159, doi: 10.1002/cncr.20212, indexed in Pubmed: 15139058.

31. Cibula D, Zikan M, Slama J, et al. Risk of micrometastases in non-sentinel pelvic lymph nodes in cervical cancer. Gynecol Oncol. 2016; 143(1): 83-86, doi: 10.1016/j.ygyno.2016.07.101, indexed in Pubmed: 27421753.

32. Slama J, Dundr P, Dusek L, et al. High false negative rate of frozen section examination of sentinel lymph nodes in patients with cervical cancer. Gynecol Oncol. 2013; 129(2): 384-388, doi: 10.1016/j.ygyno.2013.02.001, indexed in Pubmed: 23395889.

33. Zaal A, Zweemer RP, Zikán M, et al. Pelvic lymphadenectomy improves survival in patients with cervical cancer with low-volume disease in the sentinel node: a retrospective multicenter cohort study. Int J Gynecol Cancer. 2014; 24(2): 303-311, doi: 10.1097/IGC.0000000000000043, indexed in Pubmed: 24407577.

34. Sakuragi N, Satoh C, Takeda N, et al. Incidence and distribution pattern of pelvic and paraaortic lymph node metastasis in patients with Stages IB, IIA, and IIB cervical carcinoma treated with radical hysterectomy. Cancer. 1999; 85(7): 1547-1554, indexed in Pubmed: 10193945.

35. Meva J, Chaudhary RK, Bhaduri D, et al. Lacunae in International Federation of Gynecology and Obstetrics (FIGO) classification for cervical carcinoma: observational study using TNM classification as comparator. Int J Gynecol Cancer. 2013; 23(6): 1071-1077, doi: 10.1097/IGC.0b013e31829783c4, indexed in Pubmed: 23792602.

36. Hsu HC, Tai YJ, Chen YL, et al. Factors predicting parametrial invasion in patients with early-stage cervical carcinomas. PLoS One. 2018; 13(10): e0204950, doi: 10.1371/journal.pone.0204950, indexed in Pubmed: 30335786. 